\title{
Inhaled corticosteroids in COPD: Determinants of use and trends in patient persistence with treatment
}

\author{
Lucie Blais $\mathrm{PhD}^{1,2}$, Jean Bourbeau MD MSc${ }^{3}$, Odile Sheehy $\mathrm{MSc}^{1}$, Jacques LeLorier MD PhD ${ }^{1}$
}

\begin{abstract}
L Blais, J Bourbeau, O Sheehy, J LeLorier. Inhaled corticosteroids in COPD: Determinants of use and trends in patient persistence with treatment. Can Respir J 2004;11(1):27-32.
\end{abstract}

METHODS: The determinants of a new treatment with inhaled corticosteroids and secular trends in patient persistence with treatment among chronic obstructive pulmonary disease (COPD) patients were investigated. A cohort of 3768 physician-diagnosed, elderly COPD patients was selected between 1990 and 1996 from the health care administrative database of the Régie de l'assurance maladie du Québec. A nested case-control design was used to identify patient and physician characteristics that were associated with a new treatment with inhaled corticosteroids. Treatment persistence with inhaled corticosteroids was also estimated using Kaplan-Meier analysis. In addition to that, changes in treatment persistence over time, from 1990 to 1995 , were investigated by estimating the yearly proportion of patients persisting for less than one year.

RESULTS: Within the cohort, the yearly percentage of patients filling at least one prescription for inhaled corticosteroids was $42.2 \%$ in 1990 and increased to $53.1 \%$ in $1995(\mathrm{P}=0.001)$. Using a conditional logistic regression model, it was found that the patients most likely to initiate a treatment with inhaled corticosteroids were those who had severe COPD (rate ratio [RR] 1.7; 95\% CI 1.4 to 2.0), those who were hospitalized for COPD (RR 10.0; 95\% CI 5.6 to 17.9), those who consulted a respirologist in the previous month (RR 2.3; 95\% CI 1.6 to 3.3) or those who visited more than three different physicians in the previous three months (RR 1.6; 95\% Cl 1.3 to 1.9). The proportion of patients persisting with inhaled corticosteroids for less than one year rose by $19.4 \%$, from $47.6 \%$ in 1990 to $67.0 \%$ in 1995 ( $\mathrm{P}=0.011$; test for trend).

CONCLUSIONS: The use of inhaled corticosteroids increased while patient persistence decreased between 1990 and 1995. Disease severity, as well as recent consultation to a respirologist and multiple visits to a physician, were associated with a strong likelihood of being prescribed inhaled corticosteroids. The cost of this practice is far from negligible, while their clinical impact is still uncertain.

Key Words: Chronic obstructive pulmonary disease; Inhaled steroids; Medication compliance

\section{Les corticoïdes en aérosol contre la MPOC : Les déterminants de l'utilisation et les tendances de la persistance des patients au traitement}

MÉTHODOLOGIE : Les déterminants d'un nouveau traitement aux
corticoïdes en aérosol et les tendances à long terme de persistance au
traitement chez les patients atteints de maladie pulmonaire obstructive
chronique (MPOC) ont été explorés. Une cohorte de 3768 patients âgés
atteints de MPOC et diagnostiqués par un médecin a été sélectionnée
entre 1990 et 1996 à partir de la base de données administrative des soins
de santé de la Régie de l'assurance-maladie du Québec. Un modèle cas-
témoins emboîtés a été utilisé pour repérer les caractéristiques des patients
et des médecins associées à un nouveau traitement aux corticoïdes en
aérosol. La persistance au traitement aux corticoïdes en aérosol a égale-
ment été estimée au moyen de l'analyse de Kaplan-Meyer. De plus, les
modifications à la persistance au traitement entre 1990 et 1995 ont été
explorées par une estimation de la proportion annuelle de patients dont la
persistance est inférieure à an. RÉSULTATS : Au sein de la cohorte, le pourcentage annuel de patients qui remplissaient au moins une prescription de corticoïdes en aérosol s'élevait à 42,2 \% en 1990 et était passé à 53,1 \% en 1995 ( $\mathrm{P}=0,001)$. Au moyen d'un modèle de régression logistique conditionnelle, on a découvert que les patients les plus susceptibles d'entreprendre un traitement aux corticoïdes en aérosol étaient ceux qui souffraient d'une MPOC grave (ratio des taux [RT] 1,7; $95 \%$ IC 1,4 à 2,0), ceux qui étaient hospitalisés en raison de leur MPOC (RT 10,0; 95 \% IC 5,6 à 17,9), ceux qui avaient consulté un pneumologue au cours du mois précédent (RT 2,3; $95 \% 1,6$ à 3,3) ou ceux qui avaient consulté plus de trois médecins différents au cours des trois mois précédents (RT 1,6; 95 \% IC 1,3 à 1,9). La proportion de patients qui affichaient une persistance au traitement aux corticoïdes en aérosol pendant moins d'un an avait augmenté de 19,4\%, passant de 47,6\% en 1990 à 67,0 \% en 1995 ( $\mathrm{P}=0,011$, test de tendance). CONCLUSIONS : L'usage des corticoïdes en aérosol a augmenté tandis que la persistance des patients a diminué entre 1990 et 1995. La gravité de la maladie, de même qu'une consultation récente auprès d'un pneumologue et de multiples visites chez le médecin, s'associait à une forte probabilité de prescription de corticoïdes en aérosol. Le coût de cette pratique est loin d'être négligeable, tandis que ses répercussions cliniques demeurent incertaines.

${ }^{1}$ Centre de recherche, Centre hospitalier de l'Université de Montréal (CHUM) - Hôtel-Dieu; ${ }^{2}$ Faculté de pharmacie, Université de Montréal;

${ }^{3}$ Respiratory Epidemiology Unit, McGill University, and Montreal Chest Institute, Royal Victoria Hospital, McGill University Health Centre, Montreal, Quebec

Correspondence and reprints: Dr Lucie Blais, Université de Montréal, Faculté de pharmacie, CP 6128, Succursale Centre-ville, Montreal,

Quebec H3C 3J7. Telephone 514-343-6111 ext 3786, fax 514-343-5691, e-mail lucie.blai@@umontreal.ca 
In asthma, inhaled corticosteroids have become the cornerstone of therapy since the early 1990s (1), because they are of unquestionable benefit. In chronic obstructive pulmonary disease (COPD), inhaled corticosteroids have always been controversial. In the early 1990s, no study had conclusively shown the benefit of inhaled corticosteroids in COPD. Long term studies published more recently have clearly shown the absence of any worthwhile effect of these medications on the rate of change in lung function responsible for the majority of morbidity associated with this disease (2-5). High doses of inhaled corticosteroids $(3,4)$ have demonstrated acute effects on forced expiratory volume in $1 \mathrm{~s}$, but the clinical significance of this improvement remains to be seen. Furthermore, it is uncertain if long term use of inhaled corticosteroids is associated with a favourable benefit-to-risk ratio in COPD.

Despite the controversy over inhaled corticosteroids in COPD, prescription rates have been quite high (6,7). Van Andel et al (7) reported a substantial and progressively increasing prescription rate for inhaled corticosteroids in COPD patients upon enrolment in clinical trials from 1989 to 1995; the highest rate was $41.4 \%$ in 1995 . Jackevicius et al (6) found that more than $48 \%$ of COPD patients who were hospitalized with acute exacerbations and $26 \%$ of those who had stable disease had a current prescription for inhaled corticosteroids upon admission. However, information from clinical trials and hospitalized patients may not be representative of the general population. Furthermore, apart from secular trends, none of these studies have investigated the determinants of inhaled corticosteroid use among COPD patients.

To further evaluate these patterns of use, we conducted a population-based cohort study. We studied the determinants of new treatment with inhaled corticosteroids, as weIl as secular trends in patient persistence with treatment.

\section{METHODS}

\section{Data source}

Using the administrative database of the Régie de l'assurancemaladie du Québec (RAMQ), the government body responsible for the administration of health services in the province of Quebec, a cohort of physician-diagnosed COPD patients aged 66 years and older upon cohort entry was constructed. The administrative database of the RAMQ contains information on prescriptions filled at the pharmacy and on medical services dispensed either at a hospital, emergency department or medical clinic. At the time of the study - between January 1, 1990 and June 30, 1996 - the costs of prescription medications and medical services for all residents older than 65 years, with few exceptions, were covered by the RAMQ. However, between January 1, 1993 and June 30, 1996, patients had to pay a CDN $\$ 2.00$ fee for each prescription filled (8). In 1996, more than $95 \%$ of Quebec residents aged 65 years and older received health care in the universal health care program offered by the provincial govemment (personal communication, Jacques Barry, Service de la production et de la diffusion de l'information, Gouvernement du Québec). RAMQ databases have been used extensively for epidemiological studies (9-11), and the information related to medications (filled prescriptions) has been proven to be both valid and comprehensive (12).

\section{Cohort selection}

Between January 1, 1990 and June 30, 1996, 3768 physiciandiagnosed COPD patients were identified from the RAMQ database. These patients were treated either at a hospital, emergency department or medical clinic for one of the following diseases (International Classification of Diseases, 9th edition code): nonspecified bronchitis (490.0 to 490.9), chronic bronchitis (491.0, 491.1, 491.2, 491.8, 491.9), emphysema (492.0, 492.8) or chronic airway obstruction (496.9). Furthermore, to be selected, patients had to be using bronchodilators chronically and could not have a diagnosis of asthma during the study period. Chronic use of bronchodilators was defined as having at least three filled prescriptions of a short-acting inhaled beta $_{2}$-agonist, plus 180 days or more of theophylline or three prescriptions or more of ipratropium bromide over a period of 365 consecutive days. Patients entered the cohort the day that these drug criteria were fulfilled or on their 66th birthday, whichever came last. Cohort entry was postponed until the age of 66 years to ensure that there was at least one year of prior data to allow for the measurement of covariates. Patients were followed up until June 30, 1996 or until their date of death, whichever occurred first.

\section{Determinants of use and statistical analyses}

Within the cohort, the yearly prevalence of inhaled corticosteroid use was estimated from 1990 to 1995 . These prevalences were expressed as the percentage of patients who filled at least one prescription of inhaled corticosteroids in a specific year.

A case-control analysis nested into the cohort was then performed to assess the determinants of new treatment with inhaled corticosteroids. Cases were defined as new users of inhaled corticosteroids (ie, patients who were in the cohort for at least two years before they filled their first prescription of inhaled corticosteroids), and controls were defined as nonusers of these medications within the cohort. Two controls were selected per case, matched with the date of the first prescription of inhaled corticosteroids filled by the case (index date) and the year of entry into the cohort. The matching variables controlled for secular trends in the use of inhaled corticosteroids. This analysis was based on 981 new users of inhaled corticosteroids and 1962 controls identified between January 1990 and June 1996. The controls were selected by density sampling, which allows a case to be chosen as a control before he or she becomes a case and allows a subject to be selected more than once as a control to match different cases. With this sampling technique, it is possible to directly estimate rate ratios without having to invoke the rare disease assumption (13).

The variables considered as potential determinants of new treatment with inhaled corticosteroids were:

- patient demographics - age at the index date (66 to 74 years, 75 to 84 years, and 85 years and older) and sex;

- marker of COPD severity - a score measured in the three months preceding the index date. Patients were classified as severe if they had two out of the three following indicators: more than three filled prescriptions of ipratropium bromide, more than three filled prescriptions of a short-acting inhaled betaagonist, and more than 75 days of filled prescriptions of theophylline; 
- severity of exacerbations - a five-level marker of severity measured in the month preceding the index date

(level 1 - no medical evaluation required or no exacerbation; level 2 - exacerbation requiring only an antibiotic treatment [ciprofloxacin $500 \mathrm{mg}$ or $750 \mathrm{mg}$, amoxicillin $250 \mathrm{mg}$ or $500 \mathrm{mg}$, ampicillin $250 \mathrm{mg}$ or $500 \mathrm{mg}$, trimethoprimsulfamethoxazole $20 \mathrm{mg}$ to $100 \mathrm{mg}$, 80 to $400 \mathrm{mg}$, or $160 \mathrm{mg}$ to $800 \mathrm{mg}$, cefaclor $250 \mathrm{mg}$ or $500 \mathrm{mg}$, cefadroxil $500 \mathrm{mg}$, cefixime $200 \mathrm{mg}$ or $400 \mathrm{mg}$, cefprozil $250 \mathrm{mg}$ or $500 \mathrm{mg}$, cefuroxime $250 \mathrm{mg}$ or $500 \mathrm{mg}$, cephalexin $250 \mathrm{mg}$ or $500 \mathrm{mg}$, azithromycin $250 \mathrm{mg}$, clarithromycin $250 \mathrm{mg}$ or $500 \mathrm{mg}$, and erythromycin $250 \mathrm{mg}$ or more]; level 3 - exacerbation requiring a course of oral corticosteroids with or without antibiotics; level 4 - an exacerbation requiring a visit to an emergency department; level 5 - an exacerbation requiring hospitalization);

- use of physician services - consultation with more than three different physicians in the three months preceding the index date (yes or no) and consultation with a respirologist in the month preceding the index date (yes or no); and

- comorbidity score - based on drug history in the three months preceding the index date (adapted from the score published by Von Korff et al [14], in which medications for respiratory diseases were excluded).

Taking into account all of the potential determinants in the model, conditional logistical regression analysis was performed to estimate the rate ratios associated with the initiation of treatment with inhaled corticosteroids.

To characterize persistence on treatment with inhaled corticosteroids, a Kaplan-Meier analysis was performed, in which the overall proportion of new inhaled corticosteroid users still taking the medications over time was estimated. This analysis was completed within the subcohort of 981 new users of inhaled corticosteroids. Patients were followed from the date of their first prescription of inhaled corticosteroids until they stopped treatment. The assumption was made that every prescription of inhaled corticosteroids lasted for a maximum of 50 days, and that treatment was discontinued if the prescription was not renewed within three months after the end of the last renewal.

Whether patient persistence changed over time was also studied. Two analyses between 1990 and 1995 were performed: first, the yearly proportion of new inhaled corticosteroid users who did not renew their initial prescription during the study period was estimated; and second, the yearly proportion of patients using inhaled corticosteroids for less than one year was estimated (with the three-month criterion for treatment stoppage) by using the number of patients initiating treatment within a specific calendar year as the denominator. Secular trends were tested with the Cochrane test for trends.

\section{RESULTS}

In the cohort, $75 \%$ of the 3786 COPD patients were male, and the mean age $( \pm \mathrm{SD})$ at cohort entry was $74 \pm 6$ years. Distribution of age and sex was similar in the subcohort formed of the 981 new inhaled corticosteroids users: $76 \%$ of subjects were male, and the mean age was $75 \pm 6$ years.

Figure 1 presents the yearly percentage of patients in the cohort filling at least one prescription for inhaled corticosteroids between 1990 and 1995 . This proportion was $42.2 \%$ in

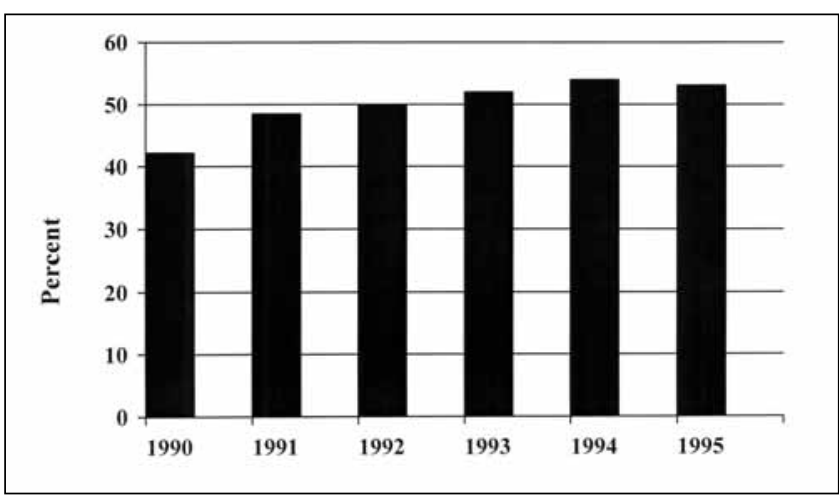

Figure 1) Yearly percentage of 3768 physician-diagnosed COPD patients who filled at least one prescription for inhaled corticosteroids between 1990 and 1995

$1990,48.5 \%$ in $1991,49.8 \%$ in $1992,52.0 \%$ in $1993,54.0 \%$ in 1994 and $53.1 \%$ in 1995 ( $\mathrm{P}=0.001$; test for trends).

Table 1 presents the results of the case-control analysis that was performed to identify the determinants of new treatment with inhaled corticosteroids. From the conditional logistic regression model, age at the index date, sex and the comorbidity score were not associated with the likelihood of initiating treatment with inhaled corticosteroids. Patients who were most likely to initiate treatment with inhaled corticosteroids were those who were identified as having severe COPD, those with at least one exacerbation requiring medical evaluation in the month preceding the index date, those who visited more than three different physicians in the three months preceding the index date and those who consulted a respirologist in the month preceding the index date. Compared with patients who had no exacerbation requiring medical evaluation, patients were more likely to initiate treatment with inhaled corticosteroids if they filled only a prescription of antibiotics (rate ratio $[R R]=4.1$; 95\% CI 3.2 to 5.2), filled a prescription of oral corticosteroids ( $\mathrm{RR}=2.6 ; 95 \% \mathrm{CI} 1.8$ to 3.9$)$, had at least one visit to an emergency department for COPD (RR=5.5; 95\% CI 2.8 to 11.1) and were hospitalized for COPD ( $R R=10.0 ; 95 \%$ CI 5.6 to 17.9) .

The more intensive the medical intervention associated with the exacerbation, the more likely the patients were to initiate treatment with inhaled corticosteroids in the next month, except for patients who filled a prescription of oral corticosteroids, who were less likely to initiate treatment than patients who filled only a prescription of antibiotics.

The analyses related to patient persistence with treatment with inhaled corticosteroids are presented in Figures 2, 3 and 4. Figure 2 shows the proportion of patients using inhaled corticosteroids continuously as a function of time from the beginning of treatment. The Kaplan-Meier curve reveals that 54\% of patients were still persisting with treatment with inhaled corticosteroids after one year, and that only $25 \%$ of patients persisted with treatment for four years or more.

Figures 3 and 4 present secular trend analyses of patient persistence. In Figure 3, the proportion of new inhaled corticosteroid users who never renewed their initial prescription increased over time, from $22 \%$ in 1990 to $30 \%$ in 1995 ( $\mathrm{P}=0.027$; test for trend). Moreover, the proportion of patients persisting for less than one year with inhaled corticosteroids rose by $19.4 \%$, from $47.6 \%$ in 1990 to $67.0 \%$ in 1995 ( $\mathrm{P}=0.011$; test for trend) (Figure 4). 
TABLE 1

Determinants of a new treatment for chronic obstructive pulmonary disease (COPD) with inhaled corticosteroids

\begin{tabular}{|c|c|c|c|c|}
\hline Determinants & Cases (n [\%]) & Controls (n [\%]) & Adjusted rate ratio & $95 \% \mathrm{Cl}$ \\
\hline Number of subjects & 981 & 1962 & & \\
\hline \multicolumn{5}{|l|}{ Patient demographics } \\
\hline 75 to 84 & $348(35.5)$ & $725(37.0)$ & 0.8 & 0.7 to 1.0 \\
\hline 85 or older & $145(14.8)$ & $309(15.8)$ & 0.9 & 0.7 to 1.1 \\
\hline Male sex & 746 (76.0) & $1488(75.8)$ & 1.0 & 0.8 to 1.2 \\
\hline No medical attention or no exacerbations & $562(57.3)$ & $1706(86.9)$ & Reference & \\
\hline Antibiotics only & $229(23.3)$ & $159(8.1)$ & 4.0 & 3.2 to 5.2 \\
\hline Oral corticosteroids* & $71(7.2)$ & $63(3.2)$ & 2.6 & 1.8 to 3.9 \\
\hline Emergency department visit for $\mathrm{COPD}^{\dagger}$ & $34(3.5)$ & $13(0.7)$ & 5.5 & 2.8 to 11.1 \\
\hline Hospitalization for COPD $\ddagger$ & $85(8.7)$ & $21(1.1)$ & 10.0 & 5.6 to 17.9 \\
\hline \multicolumn{5}{|l|}{ Use of physician services } \\
\hline
\end{tabular}

${ }^{*}$ An exacerbation requiring a course of oral corticosteroids with or without antibiotics; ${ }^{\dagger}$ An exacerbation requiring a visit to an emergency department for COPD with or without oral corticosteroids or antibiotics, but not requiring hospitalization; ${ }^{\ddagger} A n$ exacerbation requiring hospitalization for COPD with or without antibiotics, oral corticosteroids or an emergency department visit

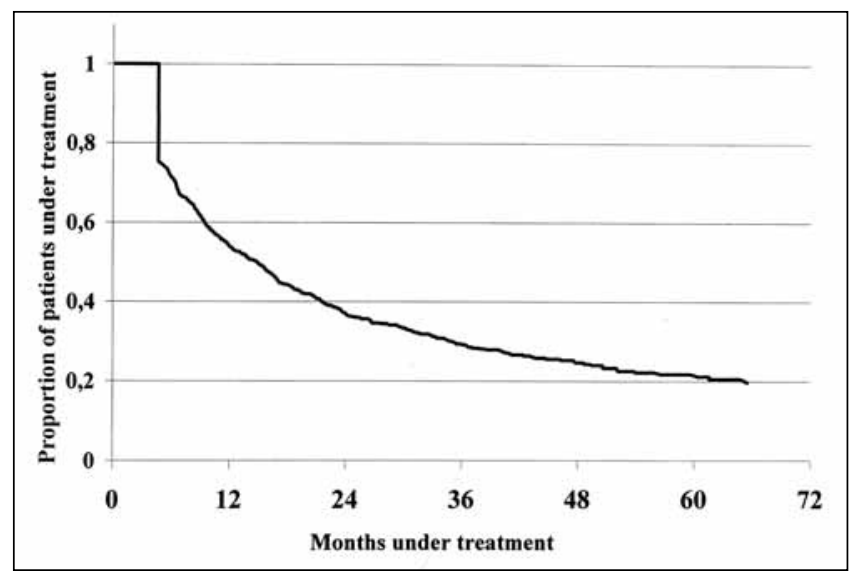

Figure 2) Kaplan-Meier curve describing the proportion of new inhaled corticosteroid users still taking the medication over time

\section{DISCUSSION}

Our data show that the use of inhaled corticosteroids increased while patient persistence on treatment decreased between 1990 and 1995. We also demonstrated that patient characteristics, such as the severity of the underlying pulmonary disease and the severity of exacerbations, as well as the use of physician services, such as visiting a respirologist and the number of physicians consulted, were all associated with a strong likelihood of being prescribed inhaled corticosteroids.

Our data on the prevalence of inhaled corticosteroid use are in accordance with the current literature. Van Andel et al (7) reported that $41.4 \%$ of COPD patients enrolled in clinical trials in 1995 were using inhaled corticosteroids at baseline, and Jackevicius et al (6) observed that more than $48 \%$ of patients hospitalized with unstable COPD had a current prescription of inhaled corticosteroids at admission. Van Andel et al (7) also reported that the observed differences over time in the use of

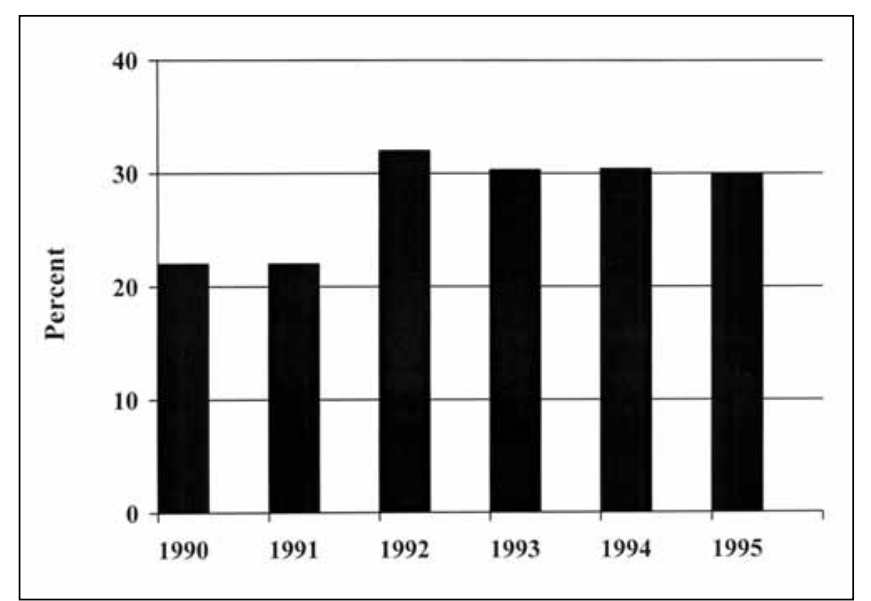

Figure 3) Yearly proportion of new inhaled corticosteroid users who never renewed their initial prescription

inhaled corticosteroids were not due to differences in severity or other characteristics of the patients. However, in these trials, the degree of disease severity in the patients was too similar to be identified as a determinant of inhaled corticosteroid use.

The present population-based study demonstrated that certain patient and physician characteristics were associated with the likelihood of filling a prescription of inhaled corticosteroids. Our analysis showed that patients with a more severe underlying disease or more severe exacerbations, as well as those who had consulted a respirologist in the previous month or visited more than three different physicians in the previous three months, were more likely to fill a prescription of inhaled corticosteroids. Thus, it may indicate that physicians tend to prescribe inhaled corticosteroids to COPD patients whose disease is not well controlled by prior treatments. 
To the best of our knowledge, the present study is the first to show that COPD patient persistence with inhaled corticosteroids decreased over time. The Lung Health Study (15) ascertained that self-reported patient persistence with inhaled bronchodilator therapy was slightly over $60 \%$ after one year of follow-up, declining to $50 \%$ after five years. In the same study, persistence measured by canister weight was about $10 \%$ below patient-reported persistence. However, inhaled bronchodilators are used for symptom relief in COPD, and the Lung Health Study participants were largely nonsymptomatic. The fact that the prevalence of inhaled corticosteroid use increased while patient persistence decreased may reflect a perceived absence of symptoms relieved by inhaled corticosteroids among COPD patients. On the other hand, the augmented prevalence may reflect the general tendency of physicians to treat airways disease with inhaled costicosteroids. Between 1990 and 1995, inhaled corticosteroid use also increased among asthma patients and came to be recognized as first-line therapy $(1,6,7)$.

Our investigation has several strengths. First, the results are easily generalizable to COPD patients, because the study is population based and not limited to specific, selected subgroups of patients. However, it is noteworthy that our cohort did not include patients younger than 65 years of age. Second, due to the large sample size, the estimates are precise. Third, our analysis estimating the determinants of inhaled corticosteroid use is based on new inhaled corticosteroid users, thus eliminating the possibility of results influenced by long term users of inhaled corticosteroids. Fourth, the RAMQ database, which includes information on prescribed medications, allowed us to reconstruct the drug history of patients over a six-year period.

Database studies also have some limitations. Patient selection was based entirely on information provided by the administrative database, and medical records were not reviewed to confirm the diagnosis of COPD. To avoid misclassification, only patients with a physician diagnosis of COPD, but not of asthma, were allowed to enter the cohort. Disease severity was classified according to the use of bronchodilators. Classification of severity recommended in practice guidelines is usually based on staging according to lung function characteristics; lung function test results were not available from the RAMQ database. However, staging based on air flow obstruction is only a general indication of the approach to COPD management. $\ln$ a given patient, most physicians do not have access to lung function tests. Overall, pharmacological therapy will be used to control respiratory symptoms. The choice between bronchodilators depends on availability and individual response, but an increase in bronchodilator treatment is usually a reflection of worsening disease severity. The severity of acute exacerbations in the present study was classified according to the requirement for medical attention, antibiotics or systemic corticosteroids and health care services. A severe COPD exacerbation has been defined in many clinical trials as an exacerbation requiring hospitalization $(4,16)$. While an exacerbation has been defined clinically in various ways in previous studies, directly collected clinical information was not available from the RAMQ database. Because drug information in our investigation was based on prescriptions filled at the pharmacy, it may not always reflect the actual intake of medication.

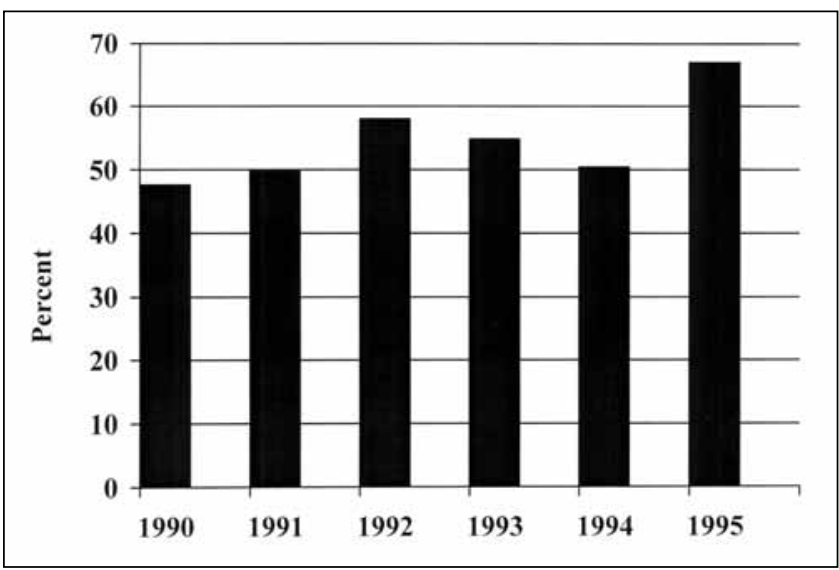

Figure 4) Yearly proportion of new inhaled corticosteroid users who were persistent for less than one year

\section{CONCLUSIONS}

The present study showed that inhaled corticosteroids are extensively prescribed to COPD patients. Inhaled corticosteroids tend to be prescribed to patients with a more severe underlying disease or more severe exacerbations, as well as to those who had consulted a respirologist in the previous month or visited more than three different physicians in the previous three months. The cost associated with this practice may not be negligible, especially when one considers the systemic adverse effects $(5,17)$ of large doses of inhaled corticosteroids that were suggested in recent clinical trials $(4,16)$. In health care systems in which costs are of concern, it would be appropriate to question the cost-effectiveness of inhaled corticosteroids in the pharmacological management of COPD patients.

ACKNOWLEDGMENTS: The authors thank Mr Jacques Barry of the RAMQ for data access. Mr Ovid Da Silva, Editor, Research Support Office, Research Centre, CHUM-Hôtel-Dieu, is acknowledged for his editorial work on this manuscript. Lucie Blais is the recipient of a New Investigator salary support grant from the Canadian Institutes for Health Research (CIHR). Jean Bourbeau is a Senior Research Scholar from the Fonds de la recherche en Santé du Québec (FRSQ), Montréal, Quebec. This study was funded by the Réseau sur l'utilisation des médicaments from the FRSQ.

\section{REFERENCES}

1. International consensus report on diagnosis and treatment of asthma. National Heart, Lung, and Blood Institute, National Institutes of Health, Bethesda, Maryland. Publication no 92-3091. Eur Respir J 1992;5:601-41.

2. Vestbo J, Sorensen T, Lange P, Brix A, Torre P, Viskum K. Long-term effect of inhaled budesonide in mild and moderate chronic obstructive pulmonary disease: A randomised controlled trial. Lancet 1999;353:1819-23.

3. Pauwels RA, Lofdahl CG, Laitinen LA, et al. Long-term treatment with inhaled budesonide in persons with mild chronic obstructive pulmonary disease who continue smoking. European Respiratory Society Study on Chronic Obstructive Pulmonary Disease. N Engl J Med 1999;340:1948-53.

4. Burge PS, Calverley PM, Jones PW, Spencer S, Anderson JA, Maslen TK. Randomised, double blind, placebo controlled study of fluticasone propionate in patients with moderate to severe chronic obstructive pulmonary disease: The ISOLDE trial. BMJ 2000;320:1297-303. 
5. The Lung Health Study Research Group. Effect of inhaled triamcinolone on the decline in pulmonary function in chronic obstructive pulmonary disease. N Engl J Med 2000;343:1902-9.

6. Jackevicius C, Joyce DP, Kesten S, Chapman KR. Prehospitalization inhaled corticosteroid use in patients with COPD or asthma. Chest 1997;111:296-302.

7. Van Andel AE, Reisner C, Menjoge SS, Witek TJ. Analysis of inhaled corticosteroid and oral theophylline use among patients with stable COPD from 1987 to 1995. Chest 1999;115:703-7.

8. Régie de l'assurance maladie du Québec. Statistiques Annuelles. Quebec: Régie de l'assurance maladie du Québec, 1996.

9. Garbe E, LeLorier J, Boivin JF, Suissa S. Risk of ocular hypertension or open-angle glaucoma in elderly patients on oral glucocorticoids. Lancet 1997;350:979-82.

10. Blais L, Desgagne A, LeLorier J. 3-Hydroxy-3-methylglutaryl coenzyme A reductase inhibitors and the risk of cancer: A nested case-control study. Arch Intern Med 2000;160:2363-8.

11. Avron J, Monette J, Lacour A, et al. Persistence of use of lipid-lowering medications: A cross-national study. JAMA 1998;279:1458-62.
12. Tamblyn R, Lavoie G, Petrella L, Monette J. The use of prescription claims databases in pharmacoepidemiological research: The accuracy and comprehensiveness of the prescription claims database in Québec. J Clin Epidemiol 1995;48:999-1009.

13. Lubin JH, Gail MH. Biased selection of controls for case-control analyses of cohort studies. Biometrics 1984;40:63-75.

14. Von Korff M, Wagner EH, Saunders K. A chronic disease score from automated pharmacy data. J Clin EpidemioI 1992;45:197-203.

15. Anthonisen NR, Connett JE, Kiley JP, et al. Effects of smoking intervention and the use of an inhaled anticholinergic bronchodilator on the rate of decline of $\mathrm{FEV}_{1}$. The Lung Health Study. JAMA 1994;272:1497-505.

16. Paggiaro PL, Dahle R, Bakran I, Frith L, Hollingworth K, Efthimiou J. Multicentre randomised placebo-controlled trial of inhaled fluticasone propionate in patients with chronic obstructive pulmonary disease. International COPD Study Group. Lancet 1998;351:773-80.

17. Lipworth BJ. Systemic adverse effects of inhaled corticosteroid therapy: A systematic review and meta-analysis. Arch Intern Med 1999;159:941-55. 


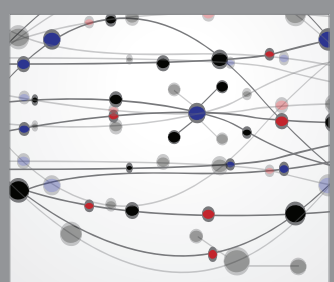

The Scientific World Journal
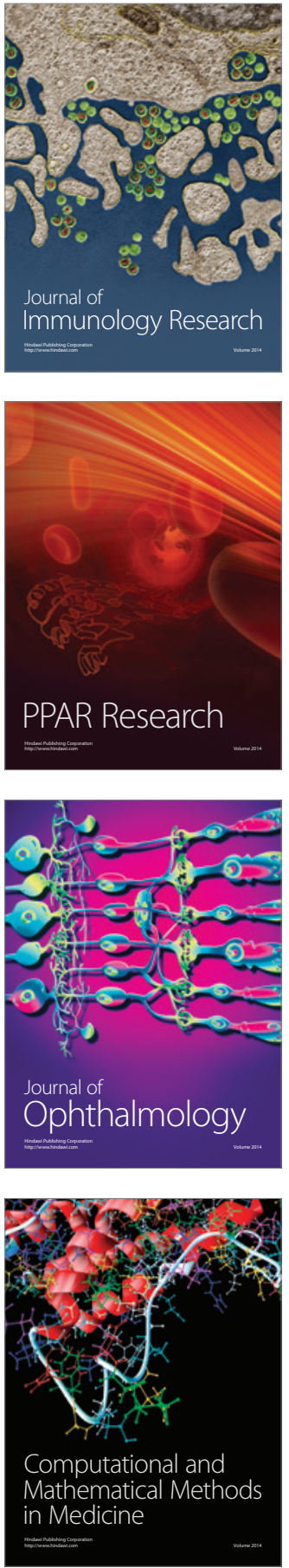

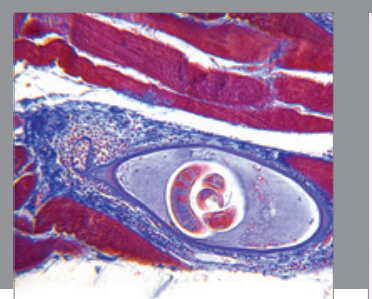

Gastroenterology Research and Practice

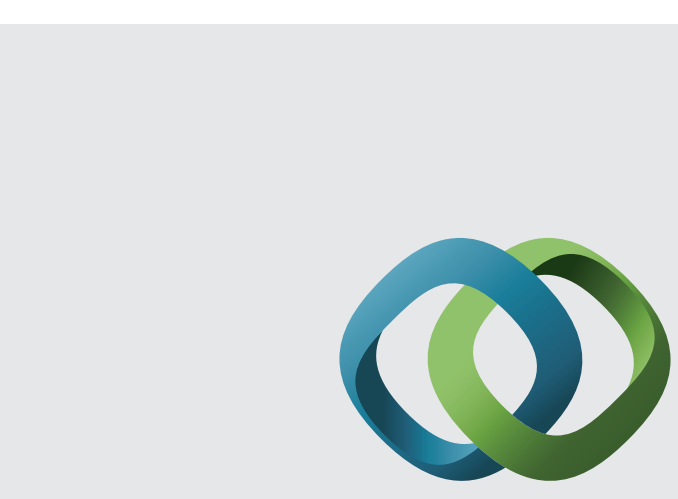

\section{Hindawi}

Submit your manuscripts at

http://www.hindawi.com
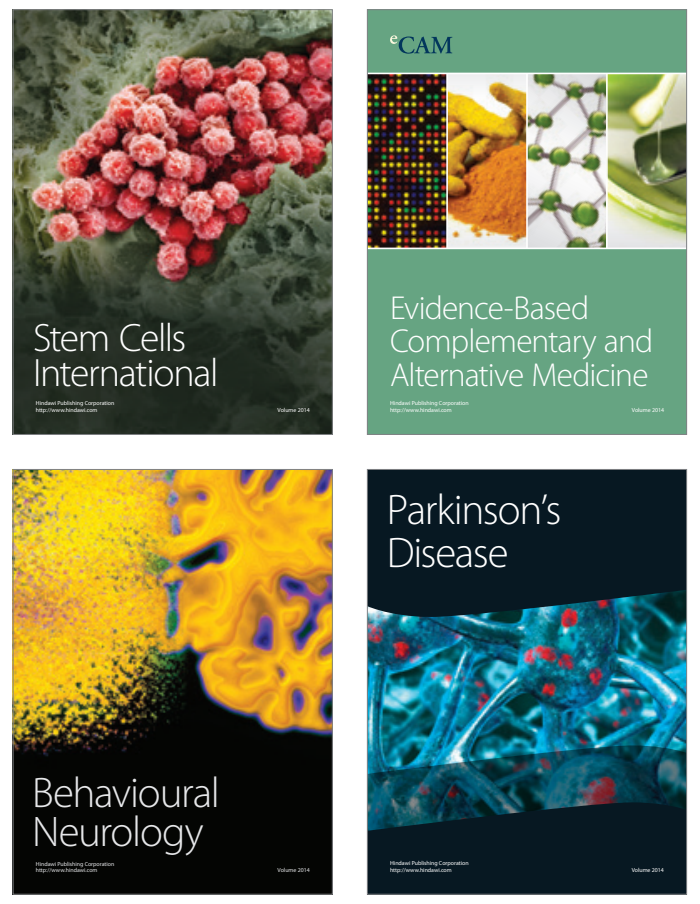
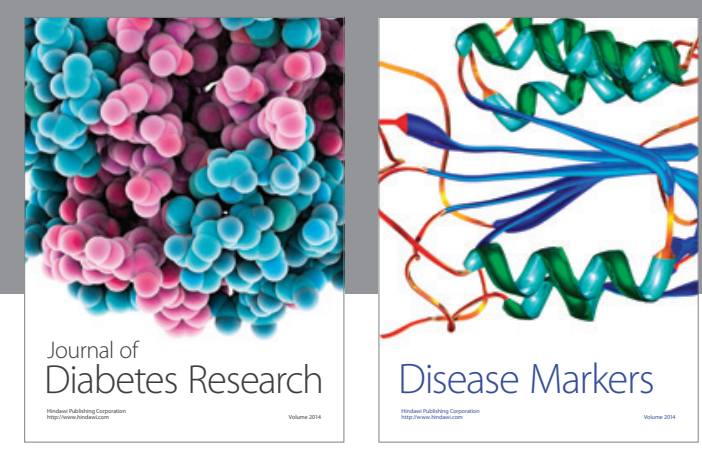

Disease Markers
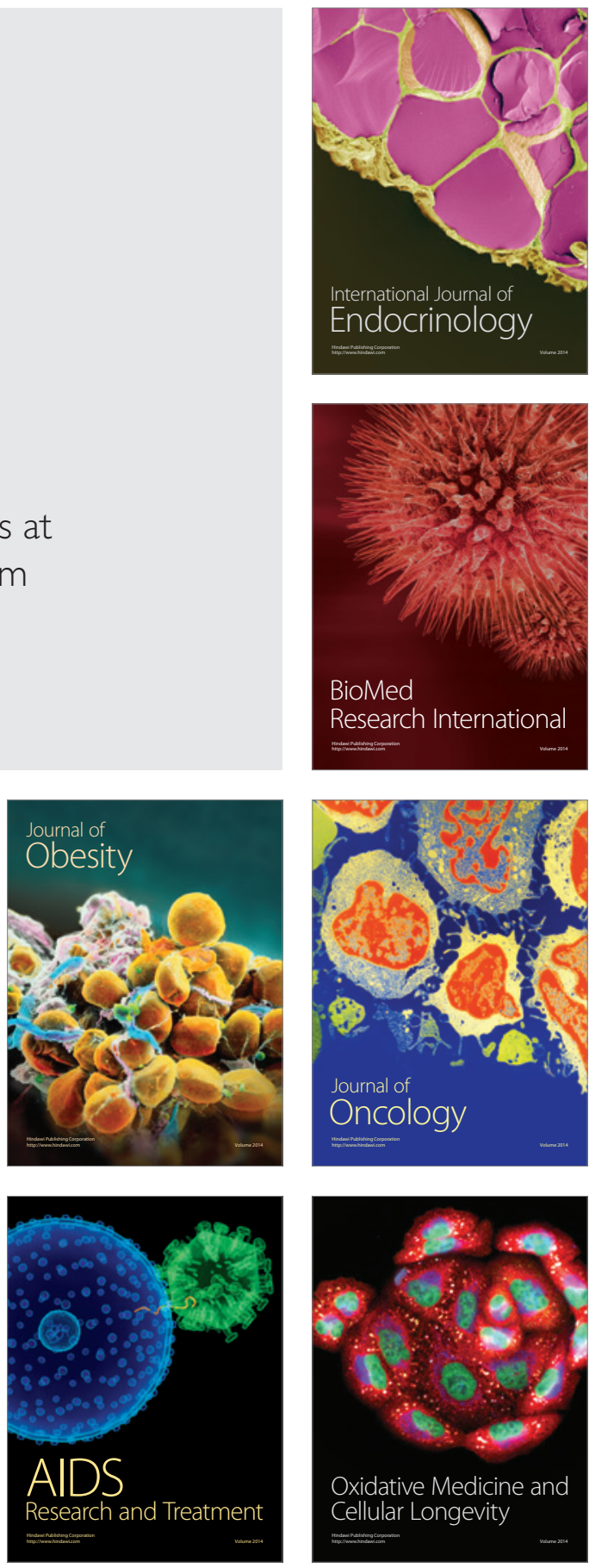